\title{
Sufrir lejos, quedarse juntos. El exilio de los uruguayos en Francia
}

Denis Merklen

Université Paris 7 - Denis Diderot

Este artículo explora la subjetividad de los exiliados uruguayos llegados a Francia a partir de 1970. El trabajo se apoya en una larga exploración etnográfica para dar cuenta de los numerosos desplazamientos que estructuran la sociabilidad del exiliado. La hipótesis general es que la pertenencia a movimientos revolucionarios de izquierda había llevado ya a los futuros exiliados a tomar distancia respecto del orden social. Esa toma de distancia se volvió ruptura con el destierro, y se reforzó más tarde, cuando el exilio se perpetuó a través de una serie sucesiva de expulsiones y rupturas.

PALABRAS ClAVE: sociología política, exilio, subjetividad, izquierda, sufrimiento, tupamaros, Francia, Uruguay.

This article explores the subjectivity of the Uruguayan exiles arrived at France after 1970. The work leans in one long ethnographic exploration to give account of the numerous displacements that structure the sociability of the exile. The general hypothesis is that the membership of at revolutionary movements of left had already the future exiles to take distance respect to the social order. That taking of distance became rupture with the exile, and was reinforced after that, when exile was perpetuated through a successive series of expulsions and ruptures.

KeYwords: political sociology, exile, subjectivity, left, suffering, Tupamaros, France, Uruguay.

Nunca se me cruzó por la cabeza adaptarme. La gente no se adapta. Vive, nomás.

El Sabalero

Casi nadie lo esperaba. Sólo unos pocos estaban al tanto. Unos ochenta uruguayos escuchaban atentos al Pepe Mujica que les hablaba ya de los desafíos del nuevo gobierno cuando el presidente de la república recién electo, Tabaré Vázquez, entró en la sala de La Parrilla. El Pepe había llegado una hora antes, caminando por la noche fría de París, cuesta arriba

1 Carvajal, José, El Sabalero: "La nostalgia es algo hereditario", Página 12, Buenos Aires, 20 de febrero de 2004. El Sabalero pasó su exilio entre Holanda y París. 
desde la estación del metro Boulets-Montreuil por la calle Voltaire. Ese 22 de octubre de 2005 la sala ya está llena y dos "compañeros" lo ven venir cansino, lento, paciente y en silencio. Casi como siempre, de vaquero y campera, si no fuera por ese secretario de traje que acompaña al recientemente nombrado Ministro de ganadería y agricultura José Mujica. El secretario viene detrás, a la rastra, como sin saber dónde ponerse en esa vereda estrecha que el Pepe ocupa codos abiertos, manos en el bolsillo. Los "compañeros" sonríen, "ahí viene" susurra el más veterano. "Buenas", llega el Pepe. Abrazos. "¿Qué hacés, Pepe? ¿Viene Tabaré?”, pregunta siempre el veterano. "Sí, viene". Entran. Sin exageraciones ni apretujones Mujica saluda a casi todos. El Pepe sube al estrado, se sienta detrás de la mesa y el Viejo lo presenta: "Buenas noches compañeros, estamos muy contentos de recibir hoy en La Parrilla al compañero... se interrumpe a sí mismo, breve silencio, sonrisa cómplice, su mirada busca la del ministro, se sonroja... Pepe, ¿qué más puedo decir? Te paso el micrófono y hablá vos?" "Muchas gracias, Viejo. Buenas noches, compañeros"... y sigue el Pepe con un discurso que se prepara para ser largo.

Fue allí, durante el discurso del viejo líder tupamaro, del guerrillero vuelto senador hace ya unos años y ahora flamante ministro del primer gobierno de izquierda de la historia, que entró el presidente de la República Oriental del Uruguay. Todos sabían que estaba en París pues la prensa no dejaba de hablar de la gira del presidente y su comitiva de ministros por Europa. Pero ver entrar allí a Tabaré Vázquez, sonriente y caminando, verlo sentarse allí, en una de las mesas en las que ellos comen, se emocionan, se emborrachan, cantan y sobre todo, sobre todo, se encuentran y conversan estos veteranos del exilio, eso no, nadie lo esperaba. El presidente en persona, el Uruguay en cuerpo y alma. Un tropel de sentimientos y emociones en cada uno de ellos. Distantes y nerviosos quedaron en el pasillo los dos custodios que el gobierno francés había dispuesto para proteger al jefe de Estado en visita. Difícilmente estos últimos hubieran imaginado alguna vez entrar así, como Pancho por su casa en este antro de las izquierdas del Sur donde se codean tupamaros uruguayos con Madres de la Plaza de Mayo argentinas, Sin Tierra brasileros con Tamules de Sri Lanka, la OLP de Palestina, vascos e irlandeses entre tantos otros.

¿Inmigrantes, extranjeros o exiliados? ¿Quiénes son esos uruguayos que se encuentran semanalmente en La Parrilla, todos los viernes, en París, en torno al asado acompañados por muchos otros argentinos, unos cuantos chilenos y, a veces, algunos paraguayos, brasileros o bolivianos? ¿Pudo el 
triunfo de la izquierda poner fin a un exilio que algunos sienten desde hace más de treinta años? ¿Qué reconoce el (primer) presidente (de izquierda) de la república con su visita a La Parrilla? Sin duda, ese encuentro entre el presidente y los uruguayos residentes en Francia se diferencia del que se produjo días después en la casa del embajador uruguayo en París. La Parrilla es la embajada del exilio, símbolo para la izquierda de una perseverancia y de una resistencia que no pueden dejar de asociarse al triunfo del Frente Amplio en las elecciones de 2004.

No me propongo aquí hacer "la" historia del exilio oriental en tierras galas. Quisiera más bien explorar la subjetividad y la sociabilidad de esas personas, describir su vivencia. Ofrecer simplemente una observación del exilio de los uruguayos en Francia tal como me parece fue vivido por muchos desde 1972 hasta ese octubre de 2005. Para ello sostendré la hipótesis de que el desgarro, el corrimiento y el desfase se encuentran entre los principales elementos que caracterizan la consternación en la que se instala el exiliado. Iremos incluso más lejos para decir que la condición de "izquierdistas", de hombres que se conciben a sí mismos como "críticos" del orden social, vuelve más agudo el sufrimiento del destierro.

El exilio fue vivido bajo una tensión subjetiva muy fuerte, que atravesó tanto la vida privada como colectiva de los uruguayos. Desde el punto de vista personal, integrarse en la sociedad francesa significaba renunciar a volver al Uruguay. Conseguir trabajo, aprender el idioma, amar las costumbres culinarias y deportivas, hacerse de amigos, participar de la vida ciudadana, respirar una nueva geografía y un nuevo clima, todo requería de un esfuerzo y de una ruptura subjetiva importantes. ¿Es posible renunciar a su identidad? Ser más puntual y más formal en una sociedad más burocratizada y en la que los ritmos de trabajo son más intensos, aceptar una separación más tajante de la vida profesional, pública y privada, fueron exigencias que se presentaron como un cambio en los estilos de vida. A la inversa, sobre el plano colectivo, perpetuar el combate político por el Uruguay significaba aferrarse a la condición de uruguayo, es decir de extranjero, lo cual implica un esfuerzo importante por mantener la distancia y la separación con la sociedad de destino. En un primer momento, esto no presentaba mayores inconvenientes: los uruguayos eran recibidos por otros compatriotas, y hasta la toma de conciencia de que el exilio se prolongaría durante años, vivir entre uruguayos y como uruguayos en París no era complicado. Bastó con hacerse de redes para obtener yerba, libros y discos, entrenar a algunos carniceros para que aprendieran a cortar asado, y el resto lo hicie- 
ron la canción popular y la literatura, manteniendo presentes como sentimiento de refugio pueblos de campaña y barrios de Montevideo en cada encuentro entre orientales. Pero una vez que la incorporación al nuevo medio social fue decantándose, los conflictos comenzaron a imponerse. Y éstos plantearon muchas tensiones y líneas de contradicción. ¿Cómo lograron los exiliados mantenerse juntos, y cómo hicieron para procesar la dolorosa experiencia del destierro? Gracias a la conversación. De modo inconsciente y casi desapercibido, la conversación se impone como una de las dimensiones fundamentales del exilio pues es gracias al diálogo que la experiencia individual se lía no sin dificultad con la vivencia de otros para dar a cada quien las palabras que le permitirán evitar el aislamiento y dar un lugar a lo arbitrario. Pero no siempre hablando se entiende la gente y la conversación no lo arregla todo.

\section{Breve racconto de por qué y cómo los uruguayos llegaron a Francia}

Prácticamente con la sola fuerza de su voluntad, Alain Labrousse había organizado ya hacia 1971 toda una actividad de denuncia de la represión que comenzaba a ejercerse en Uruguay contra la izquierda. Labrousse había vivido la movilización estudiantil en 1968. Trabajaba entonces en el Liceo francés de Montevideo como joven cooperante y desde ese lugar no sólo había podido observar una movilización política que habría de encantar a muchos jóvenes intelectuales en Europa y América Latina, la guerrilla de los tupamaros. ${ }^{2}$ También le tocó asistir al modo acelerado en que el gobierno de Jorge Pacheco Areco limitaba las libertades públicas para girar hacia un régimen feroz. Observó entonces la acción de los "escuadrones de la muerte", el vuelco de la acción policial hacia la represión clandestina, en fín, el Golpe de Estado del 29 de junio de 1973 y la instalación de la dictadura militar que generalizaría la tortura, la prisión y los asesinatos en un clima que prefiguraba ya las operaciones del "Plan Cóndor". Alain Labrousse volvió a Francia en 1971 convencido de que la represión sería cada vez más acentuada, a medida que el poder del Partido Colorado se

2 El "Movimiento de liberación nacional - Tupamaros" se lanza a la lucha armada en el Uruguay en 1963 alcanzando un peso político muy importante entre 1969 y 1971. Fue aplastado por la represión hacia fines de 1972. Actualmente los tupamaros constituyen el primer grupo político del gobierno de la izquierda en Uruguay. A. Labrousse es el autor del primer libro sobre la guerrilla uruguaya en francés: Les Tupamaros: guérilla urbaine en Uruguay, Seuil, Paris, 1971. 
agotara y crecieran las fuerzas de contestación representadas por la guerrilla de los tupamaros, por la izquierda reunida en el Frente Amplio y por el clima de revuelta que ganaba rápidamente las organizaciones sindicales y estudiantiles. Había asistido a las denuncias en el parlamento de la tortura sistemática y a varios asesinatos a manos de las fuerzas policiales, de las fuerzas armadas o de los escuadrones de la muerte. Algunos de esos crímenes tendrían gran repercusión: el del estudiante Líber Arce en una manifestación, el de ocho militantes reunidos en un local del Partido Comunista, el de varios tupamaros torturados y arrojados muertos en la vía pública.

El exilio uruguayo en Francia se vio así alimentado por tres grandes oleadas: una primera tanda llega entre 1972 y 1976, son esencialmente tupamaros y otros grupos armados, y son relativamente pocos - menos de cien personas- . A partir de 1977 llega una segunda tanda más numerosa en la que se destacan los militantes y simpatizantes de otros grupos de izquierda (sobre todo comunistas) o sindicalistas, e incluso algunos miembros del Partido Blanco. Este segundo grupo es alimentado por la nueva ola represiva lanzada por la dictadura en Uruguay, y por quienes son masivamente expulsados de Argentina tras el golpe de estado del general Videla en ese país. Por último, una tercera tanda viene de Cuba. Se trata mayoritariamente de tupamaros que, habiendo llegado a Chile antes de 1973, se refugian una segunda vez en Cuba expulsados por la dictadura del general Pinochet. Finalmente, la prolongación de la estadía cubana en condiciones de aislamiento los lleva a quitar "la isla" hacia Europa a finales de los años setenta. ${ }^{3}$ Los primeros exiliados llegaron a Francia en 1972, antes de la dictadura, y se encontraron entonces en París con el embrión de lo que sería una de las principales organizaciones de defensa de los derechos humanos: el Comité de defensa de los presos políticos en el Uruguay (CDPPU). Pronto se convertirían en el grupo que más fuertemente marcó la presencia uruguaya en París, pero entonces no era más que un puñado de militantes vinculados a la constelación tupamara. A medida que el flujo de exiliados comienza a aumentar, el "Comité" va sumando otras tareas a la de denunciar las violaciones de los derechos humanos cometidas por el gobierno de

3 Con la esperanza de reagruparse y fortalecerse a fin de luchar contra la dictadura, un importante número de tupamaros se refugia en Cuba tras el golpe de estado de Chile. Pero este refugio se hace en condiciones de clandestinidad, lo que impide a los refugiados integrarse en la sociedad cubana. Cuando comprenden que toda tentativa de regreso al Uruguay es suicida, deciden dejar Cuba. Para ello, muchos viajan hacia países del Este europeo e ingresan clandestinamente en Francia para pedir el definitivo refugio político. 
Pacheco en un primer momento y posteriormente por la dictadura de José María Bordaberry. ${ }^{4}$ Por una parte juntan fondos con el objetivo de ayudar a las familias de los presos, y por otra, se organizan para socorrer a quienes van llegando a un país extranjero sin dinero, sin trabajo y, en la inmensa mayoría de las veces, sin conocer el idioma. Así quedó estructurada para siempre la acción colectiva de los exiliados: "seguir la lucha por el Uruguay" enviando fondos y llevando la voz del Uruguay al espacio público europeo, y "ser solidarios con los compañeros" ayudando a la integración social de las familias y los individuos en el trabajo, en el albergue, el equipamiento del hogar, la orientación en el nuevo espacio social; y creando espacios comunitarios como la Casa del Uruguay o La Parrilla.

No es posible establecer con precisión el número de exiliados que llegaron o que se establecieron en Francia, como no ha sido posible establecerlo fehacientemente para ningún otro de los países que acogieron el exilio uruguayo. Un trabajo sobre los registros de los distintos grupos de exiliados en París y sobre la base de diversos testimonios lleva a pensar que los exiliados uruguayos en Francia no sobrepasaron en mucho las mil quinientas personas, concentradas esencialmente en la región parisina, con algunos otros núcleos en Marsella y Toulouse, y en menor medida en Lyon. ${ }^{5}$ El hecho de tratarse de un grupo relativamente pequeño de personas tuvo un efecto importante respecto a la experiencia social que nos interesa. Los uruguayos vivieron su exilio de un modo que preferimos llamar "pueblerino" o "barrial" más que "comunitario", donde lo esencial era que "todo el mundo conoce a todo el mundo". Sobre la base de esa sociabilidad pueblerina o barrial, los exiliados debieron procesar al mismo tiempo la experiencia común del destierro junto con una serie de diferencias que no fueron tan lejos como para concebir el exilio como una vivencia singular, pero sí lo suficiente como para alimentar divisiones duraderas entre los individuos, los grupos y las familias. Muchas de esas divisiones estaban fundadas en los clivajes previos que introdujeron las pertenencias políticas. Así, el exilio uruguayo en Francia se organizó principalmente entre el polo

4 Electo a finales de 1971, José María Bordaberry (Partido Colorado) asume el poder en marzo de 1972. En junio de 1973 disuelve las cámaras, clausura definitivamente las libertades públicas y organiza la dictadura con apoyo militar. Pronto, los propios militares asumirán el gobierno del país desplazando a Bordaberry e instalándose en el poder hasta finales de 1984.

5 Sobre los distintos destinos del exilio uruguayo, véase el trabajo colectivo publicado bajo la dirección de Dutrénit Bielous, Silvia: El Uruguay del exilio. Gente, Circunstancias, Escenarios, Trilce, Montevideo, 2006. Sobre el caso francés, ver en el mismo volumen Allier Montaño, Eugenia, y Merklen, Denis: "Milonga de andar lejos. Los que se fueron a Francia", págs. 340-369. 
de los tupamaros, que constituyó el primer grupo, el más numeroso y el más influyente, y el polo de los Frenteamplistas con fuerte predominancia comunista. ${ }^{6}$ Pero por debajo ésta división objetiva estaba marcada por una serie de fracturas subjetivas que estructuraban la experiencia de un modo tal vez más profundo.

\title{
Soltar la lengua
}

\author{
Dedos son dedos, \\ días son días, \\ madres son madres, ¡madres! \\ hijos son crías, \\ los pensamientos son todos míos \\ pero mi lengua \\ ya no es tan mía \\ Rúben Rada: "Dedos"
}

\begin{abstract}
"Había dos tendencias diferentes. La línea de ruptura era: los que se integran y los que no se integran. Había unos que se integraban al punto que no querían hablar español para poder hablar bien francés, que sólo tenían amigos franceses y que se querían integrar cueste lo que cueste. [...] Los otros se refugiaban en el español y no querían hablar en francés. Era un rechazo total. Sentían que hablar en francés era como aceptar la condena del exilio. Yo creo que los que vivieron en comunidad lo necesitaban, eran los que tenían menos capacidad de abrirse al mundo".?
\end{abstract}

La censura moral a quienes primero se fueron integrando fue muy grande: "te estás afrancesando" equivalía a "te estás aburguesando", "nos estás traicionando" y podía ir hasta "estás traicionando al país", o "te olvidás de los que quedaron allâ". La vida política de todos los grupos, fueran éstos comunistas, tupamaros u otros, requería de una adhesión sin restricciones a la orientalidad, que fue evidentemente exacerbada. El uruguayo se volvía más oriental que el postre Chajá o era rápidamente olvidado por sus compañeros de desventuras. El proyecto político y la identidad revolucionaria pasaron muchas veces a depender del gusto por el mate amargo, y resultaba prácticamente evidente que el amor al rugby implicaba una trai-

6 Estos dos grandes sectores se organizaron en torno a diversas entidades como los ya mencionados del lado "tupamaro" o la asociación France-Amérique latine del lado comunista. También hubieron otros grupos independientes de este clivaje como el movimiento de juristas reunidos en el CIJAU.

7 Exiliado Tupamaro, proveniente de Cuba, regresó a Uruguay en 2005. 
ción de principios que sólo el fútbol podía garantizar. La asociación entre estarse afrancesando y estarse aburguesando nos ofrece el punto de vista por el que el exiliado se diferencia del inmigrante. No hay duda de que, desde un punto de vista formal, existe una diferencia radical entre quien se juega la vida en el destierro (el exiliado) y quien parte, en el anhelo o en la desesperanza, tras nuevos horizontes (el inmigrante). Pero desde un punto de vista subjetivo, la experiencia del exilio agrega una matriz política con la que todos son llevados a leer la realidad. Así, la "integración social" del inmigrante, el afrancesamiento, se convierte en aburguesamiento.

La tensión atravesó evidentemente a cada persona de modo distinto. De los que no volvieron al Uruguay, unos evolucionaron desde la identidad del exiliado a la de inmigrante, los otros quedaron "exiliados para siempre". El exiliado está transplantado, forzado a residir allende la mar, permanece en estado de flotación con relación a la sociedad que lo cobija y ajeno al país que lo expulsó y al cual no puede renunciar a pertenecer. El inmigrante aterriza finalmente en Francia porque decide un día irse del Uruguay. Ya no sufre el exilio, padece de la inmigración.

Corre el año 1999 y ayudamos a un amigo, exiliado en 1974, a pintar el salón de la casa que acababa de comprar en Fontenay-sous-Bois y que se prepara a pagar con un crédito a veinte años. Quince años han pasado ya desde el fin de la dictadura, y del exilio. Nuestro amigo tiene hijos que crecen, se integra, se endeuda. Pensativo en las raíces que está echando en tierras galas, nos dice: "no sabemos si hacerle una pieza a Mónica [la hija menor que nació en París] para cuando crezca, porque el problema es que no sabemos si nos volvemos o nos quedamos"... Justo en el momento de instalarse, tras veinticinco años de vida en Francia, viene la duda. ¿Es esto definitivo? ¿Está el Uruguay perdido para siempre? Así como el inmigrante niega la ruptura de sus lazos con el país de origen, al exiliado le cuesta aceptar el fin de su condición de exiliado. Esta tensión fue atravesando a unos y a otros en diversos grados y en distintos momentos, en función de los más variables episodios, entre los cuales enamorarse fue uno clave. Encontrarse diciendo je t'aime no estuvo nunca exento de consecuencias. La disyuntiva también atravesó familias y parejas que se veían confrontadas al problema de sus hijos: niños que habían nacido en Francia, que iban a la escuela en París y que eran alfabetizados y socializados en francés... ¿se podía exigir de ellos que añoraran las puestas de sol en la bahía de Montevideo? Pero dado que el exiliado organizó su vida en una primera etapa en torno a la pertenencia a un grupo de compañeros, la tensión llevó 
siempre la marca de un conflicto unas veces perverso y otras borroso entre vida privada y vida colectiva. En ese sentido, el combate político de los exiliados retiene a las personas en un estado de separación de la sociedad en la que viven que no puede durar. En uno de sus últimos discos, Daniel Viglietti dedica una canción a su hija nacida en París de padre uruguayo y madre francesa. Con una gran ternura el autor pone en evidencia toda la ambivalencia de la que hablamos: mi niña nació de noche por mañana / el norte la concibe y el sur la llama / y el sur la llama. ${ }^{8}$

En un primer momento el exiliado se adhiere a esa distancia con la sociedad pues ella reproduce o continúa la distancia con la que los militantes construyeron su relación con la sociedad ya en el Uruguay. Si para la mayoría de los uruguayos el exilio debía ser "una manera de entender la lucha contra la dictadura", esto también debía significar una forma de vida o de supervivencia económica: conseguir un trabajo era una cuestión central. Era necesario ganarse la vida, lo que imponía ya una condición de integración, lo quisiera el exiliado o no. Pese a llegar a una Francia de pleno empleo, la situación no fue fácil. Es cierto que hubo un pequeño grupo que tuvo la vida más llevadera. Es el caso de los científicos, quienes revalidaron sus títulos y pudieron entrar en universidades, institutos de investigación y hospitales. Los militantes, en cambio, llegaron sin trabajo y sin relaciones. Muchos eran muy jóvenes y no habían tenido tiempo de terminar sus estudios. El grueso de los exiliados en Francia debieron "reconvertirse" o encontrar empleos no calificados: porteros, recepcionistas de hotel, encargados de cafeterías, lava-platos en cafeterías y restaurantes, plomeros, albañiles, maestros de idiomas, limpieza. Como dice un exiliado, "se trataba de pequeñas 'bandas' que se ayudaban entre sí para encontrar trabajo". En Tristes tropiques, Claude Lévi-Strauss observa ya con justeza que el desplazarse de una ciudad a otra conlleva siempre una desclasificación social: "sea en más o en menos, en el sentido de una mejora de la condición material o en el de su deterioración, se necesitaría un milagro para que el viaje no correspondiera a ningún cambio. Al mismo tiempo que transporta a miles de kilómetros, el viaje hace subir o bajar algunos grados en la escala del estatus. El viaje desplaza, pero también desclasifica — para bien o para mal- y el color y el sabor del lugar no pueden ser disociados del rango siempre imprevisto donde él nos instala para saborearlos". ${ }^{9}$ En la

8 Viglietti, Daniel: "La canción de Trilce", en el disco Esdrújulo, Ayuí, Montevideo, 1994.

9 Lévi-Strauss, Claude: Tristes tropiques, Plon, Paris, 1984 (1ère éd. 1955), pág. 93. La traducción es mía. 
experiencia del exilio ese desplazamiento/desclasamiento adquiere una dimensión muy importante dada por la violencia de una partida que lleva a resistir toda adaptación, sea porque se la vive como una derrota política, sea porque se carece del proyecto con el que el inmigrante orienta la percepción de su viaje. Esa radicalidad de la situación del exilio se expresa fundamentalmente en la cuestión del idioma. Toda la relación con la sociedad de destino, y los desplazamientos de una posición social a otra que el destierro conlleva, aparece bajo un aspecto lingüístico. El idioma es en primer lugar una barrera importante para la integración laboral y personal en Francia. Pero no sólo para ello. En las relaciones de los exiliados con sus hijos, nacidos y socializados en Francia, o con sus compañeras también se presentó este problema. Si bien los uruguayos de aquellas generaciones estudiaban francés en el liceo, la gran mayoría no contaban con un manejo suficiente del idioma como para desenvolverse en la vida cotidiana. Para éstos la falta de fluidez significó una profunda "herida narcisista". El capital lingüístico del que disponían los exiliados los llevó a ver disminuidas sus capacidades de expresión y de lucha en las interacciones cotidianas, a verse subrepticiamente desarmados frente al otro. Y detrás de esta adquisición del idioma se halla la de los códigos culturales y la de las normas sociales. Si para los hijos de exiliados, llegados con pocos años o nacidos en Francia, esta apropiación fue más fácil, para los adultos con más de veinte o treinta años no fue nada evidente.

El desconocimiento del idioma, la falta de trabajo, la soledad y la distancia con los seres queridos, la nostalgia por los olores, los colores, los sabores y los lugares dieron a la experiencia del exilio una ambivalencia continua, un torbellino de sentimientos encontrados. Frente a las dificultades de la vida cotidiana, la posición particular del exiliado llevó incluso a situaciones muy difíciles: encierro identitario, sectarismos, brotes sicóticos, intentos de suicidio. Claro que no puede decirse que la generalidad haya alcanzado tal dramatismo. El exilio conllevó una gran cuota de sufrimiento social y psicológico, pero unos y otros contaban con distintos medios para afrontar estos conflictos. Para quienes eran militantes políticos confirmados, el exilio era algo duro, que se sufría, pero podía ser vivido como una consecuencia del compromiso político. La identidad que confiere la lucha significó para muchos un soporte subjetivo esencial, y sobre todo, como vimos, ofreció una matriz de lectura de lo que estaba sucediendo. Pero muchos se vieron compelidos al destierro sin poseer una sólida formación política o sin hacer del análisis político la clave que permite des- 
cifrar todo misterio. Para estos últimos, la experiencia del exilio apareció como algo incomprensible. Sin embargo, pese a la diversidad de situaciones todos los entrevistados coinciden en señalar que la comunidad de exiliados constituyó una verdadera tabla de salvación. "Hubo una enorme dependencia económico-afectiva de todo el mundo". Para la mayoría de los uruguayos la vida política y la personal eran una sola, estaban juntos para todo y juntos iban a todos lados.

\section{El exiliado, un extraño extranjero ${ }^{10}$}

Encontramos al "Francés" en casa del "Viejo" Díaz, uno de los notables de la colonia. Un asado en la periferia sur de París. Es domingo en el verano de 2003 y el encuentro reúne cinco uruguayos, un francés y una argentina. El francés se llama Jean-Pierre, nació en un valle de los Alpes y vive... en Montevideo (está de visita en París con Élida, su compañera, una uruguaya exiliada durante veinte años en París). En cambio el "Francés" es un uruguayo a quien sus compatriotas llaman así. Es hijo de españoles, se llama Pedro y nació... en Limoges. ¡Qué historias! ¿Será el exilio, parcialmente al menos, un conjunto de subjetividades rehechas, de resocializaciones tardías? Sin duda, pero ¿qué relación existe en este caso entre historia colectiva y biografía?

Como éste son muchos de los encuentros de los uruguayos que viven en Francia, pero veamos quién es quién en este asado. Veremos enseguida que las trayectorias sociales de cada persona confieren una complejidad extraordinaria a esos encuentros sociales. Hay tres parejas y un soltero (el "Francés"). Luciana y Denis vinieron a estudiar en los años noventa. Son la excepción, aunque Denis también es uruguayo, hijo de exiliados en Argentina. El resto de los convidados tiene más de sesenta años. Los dueños de casa, los Díaz, vinieron al exilio francés hace treinta años, en 1974. Tienen un hijo, de los mayores de la colonia, que nació en París, lleva Daimán como segundo nombre, casi no conoce el Uruguay y ahora vive en Tokio, donde fue a perfeccionarse en informática y se quedó luego a trabajar en Japón. Jean-Pierre se casó con Élida, otra uruguaya exiliada en los años setenta. Se conocieron en París y una vez jubilados, de jubilación

10 Los nombres mencionados en esta sección han sido cambiados a fin de proteger la identidad de las personas. 
francesa, se fueron a vivir a Montevideo cuatro años atrás, "para estar cerca de los hijos" que Élida tiene en Uruguay de un matrimonio anterior.

El "Francés" llegó tarde al asado, "porque ya no recordaba cuánto demoraba el metro en llegar". Hace poquito que regresó de Montevideo y está viviendo en la casa de uno de sus hijos, en el norte de París. Ni bien llegó, el "Francés" se quedó afuera con el "Viejo" Díaz, mientras el resto de la reunión disfrutaba del aperitivo en la veranda. Ellos fuman, toman vino y conversan de la cana. Militantes del MLN, los dos estuvieron en la cárcel de Punta Carretas e inevitablemente rememoran episodios y compañeros. $\mathrm{Al}$ anecdotario se agregan dos preguntas que, como siempre en estos casos, conducen el diálogo. La primera actualiza la unión, restablece la complicidad, renueva el lazo eterno por evocación de momentos compartidos: "¿Te acordás de Fulano?” Esta primera pregunta está destinada a repetirse hasta agotar las horas del encuentro y las botellas de vino, parece que la totalidad de los momentos vividos juntos fueran revisitados. Tiene variantes y complementos: “¿Y Sutano?... ¿y te acordás de la vez que Fulano y Sutano agarraron a Mengana para la joda? ¿y cuando Mengano se agarró a las piñas con Fulano?"

Otra pregunta, también destinada a la repetición, busca reunir los trozos dispersos por años de rupturas sucesivas, avatares y distancias: "¿Qué sabés de tal?, hace años que no lo veo, me dijo Mengano que andaba por México...” “¿Y el 'Flaco’? ¿qué sabés de él? ¿cómo anda la mujer? ¿me dijeron que andaba con problemas de salud? iQué loco increíble ese! ¿Pahhhh, ese sí que es de fierro!" "Che, me dijeron que el 'Gordo' y la 'Renga' se habian separado... Qué joda, ¿no? ¿Y los gurises? Siempre tuvieron problemas con la más grande, nació en la cana, pobre gurisa.

Los encuentros de antiguos exiliados tienen eso como primera característica: la repetición. Evocar anécdotas y aventuras, muchas veces teñidas por el humor, es tal vez un modo de conjurar dolores y desgarros. Porque el exilio estuvo hecho de eso y debe encontrarse un modo de exorcizarlo. Las reuniones parecen idénticas entre sí. A los mismos diálogos guiados por las mismas preguntas, se agregan las figuritas repetidas de unos personajes que son siempre los mismos: la redundancia de unos amigos y camaradas de generación que se hicieron compañeros políticos y de aventura para volver a hacerse amigos de desventura años más tarde y añorarse finalmente en la distancia. Ese ciclo en tres tiempos marca el ritmo de una zamba que se repite, media vuelta y vuelta entera. Y como los encuentros son siempre de comilona, la redundancia se refuerza con idénticos platos que 
siempre evocan el Uruguay, la juventud y la infancia, las mismas bebidas que facilitan llegar al estado de ánimo de la reunión anterior, "la última vez que nos vimos". Y el tabaco que deja resbalar el silencio como si no fuera tal. El humo fija las ausencias que flotan desdibujadas entre las miradas de todos. En las reuniones sociales el antiguo exilio muestra la superficie agujereada de una sociabilidad que intenta restituir todo lo que no está. Tal vez por ello la repetición del mismo anecdotario no pueda más que reproducirse conversación tras conversación.

La militancia de los años mozos, el pasado en el Uruguay y el exilio sólo pueden conjugarse en pasado imperfecto, son repetitivas evocaciones que permanecen en un presente continuo. Las noticias del Uruguay de hoy van mechadas entre bocado y bocado. Si Michel de Certeau fuera invitado a uno de estos encuentros cotidianos moriría de envidia por no poder hacer la sociología de una vida cotidiana que inasequible porque no transcurre aquí, no está ahí en lo que él podría ver y oír. ${ }^{11}$ La vida cotidiana del exiliado está cargada de sentidos que no corresponden con la situación presente: provienen de otro tiempo y de otro lugar, de otra cultura, y de una experiencia que formó a las personas para actuar en un contexto que ya no es. ¿Cómo una imagen del Cerro organiza la experiencia de Montmartre?

Tal vez en eso está la más paradójica de las tragedias por las que está atravesado el exiliado: es un hombre desplazado, vive doblemente décalé. Él cree que la vida se le quedó en el Uruguay, en un Uruguay del cual tiene plena conciencia que ya no existe. Le duele cada vez que viene un joven del barrio la Teja de hoy que no sabe qué quiere decir fiaca, aunque la panza le cruja. ${ }^{12}$ El presente de su tierra transformada lo confronta a la tragedia de una identidad que añora algo que no existe. Y esa evocación infantil se redobla en el exiliado del desplazamiento forzado a una tierra no deseada: "Dolor, sentir/ como rebrota la infancial esa oscura distancia que/ nos quemaba la vida ayer/ y hoy es fuente de amor". ${ }^{13} \mathrm{El}$ primer corrimiento en la identidad del exiliado se produce en el encuentro entre la mirada que él tiene del Uruguay y la que los uruguayos tienen de él. Esos uruguayos que escrutan a veces no sin cierta perversidad sus signos de afrancesamiento. Pero este primer desplazamiento está redoblado por otro.

11 De Certeau, Michel; Giard, Luce, y Mayo, Pierre: L'invention du quotidien, Folio Essais, París, 1990

12 Fiaca: hambre en el lunfardo uruguayo de los años setenta.

13 De la canción "Volver", de José Carvajal "El Sabalero", compuesta en Holanda hacia 1980 se convirtió en uno de los emblemas del exilio uruguayo. 
La mayor parte de los uruguayos que están aún en Francia están perfectamente integrados en la sociedad francesa. Allí viven, trabajan, crían a sus hijos, votan, leen el diario, miran televisión, disfrutan de las protecciones sociales; en fin, se integran. Pero el antiguo exiliado se siente radicalmente diferente del francés: no es lo mismo, ellos son franceses. Y evidentemente, el exiliado es visto desde la diferencia, se lo coloca en la condición de simple extranjero por los nacionales que no pueden más que regocijarse en los defectos de su fonética y su gramática, como quien se complace en la inhumanidad del estigmatizado. Si hoy el que antes fuera exiliado devino en simple inmigrante, su condición de antiguo exiliado no deja de pesarle. Es en ese sentido que muchos exiliados quedan varados en esa condición, aun cuando las condiciones de persecución política se hayan extinguido en el país de origen.

¿Cómo se procesa la experiencia de la "proletarización" en una sociedad de la abundancia? El "Viejo" Díaz era escribano en el Uruguay de los años setenta. Tenía un estudio en una de las zonas más reputadas de la capital, en una de las esquinas de la Plaza Matriz. Militante tupamaro, cayó preso en 1971 y fue encerrado en la cárcel de Punta Carretas. En 1974 salió con la "opción", rumbo a España con su mujer. Como un "terrorista" fue subido al avión, esposado, con un pasaporte que fue entregado a la tripulación. Llegó a salvo. Sin embargo, el Madrid de Franco no resultaba tierra muy propicia para quien seguía considerándose a sí mismo como un militante. Decidieron ir a París, donde ya funcionaba el CDPPU. Entre los techos de un edificio de la calle Mouffetard consiguieron una pieza en la que se instalaron: "La pieza y la cama eran tan chicas que yo dormía con el filo de fierro de la cama atravesado en la 'espalda' - por no decir otra cosa-, y un día le dije a mi mujer: 'Te juro que en la cana estaba mejor'. ¡Hasta hoy no me lo perdona!".

Pocos días después consiguió un trabajo como lavacopas en un restaurante. Si bien es cierto que su diploma no posee ningún valor en un país extranjero, el "Viejo" no hizo ningún esfuerzo por conseguir un trabajo acorde a sus competencias y calificaciones, alguna suerte de trabajo no manual. Al tiempo comenzó a trabajar en la construcción, esencialmente como electricista, pero en realidad como obrero independiente. Como tantos otros inmigrantes, el Viejo es polivalente: pintura, carpintería, electricidad, nada se le escapa dentro del marco de pequeñas reformas e instalaciones domésticas o de pequeños comercios. Siempre trabajó junto a otros uruguayos, argentinos, chilenos, algún peruano, español o colombiano. 
Nunca lo acompañó un francés. Hasta que se jubiló y volvió al Uruguay en 2006, hizo incluso funcionar una pequeña empresa de la cual él fue el único empleado, y que le permitió escapar al trabajo en negro. Esta "proletarización" está sin duda asociada a un deterioro de su salud con el que paga el precio de muchas horas de trabajo físico sumado a las interminables horas de militancia y a las secuelas del paso por la cárcel.

Esta segunda "opción", personal esta vez, es un camino transitado por muchos, y las encrucijadas que lo atraviesan van más allá del caso del Viejo. Por una parte muestra la fuerza del grupo sobre el individuo que asume con la "proletarización" el respeto de una voluntad política colectivamente definida; pero por la otra, esa "proletarización" muestra también una estrategia de inscripción social en el exilio. En efecto, apoyándose en el compromiso militante asumido, la "proletarización" se convierte en un modo que tiene el exiliado de dar prioridad a la inscripción "comunitaria" en el grupo de militantes exiliados sobre una opción de integración en la nueva sociedad. Por medio del "sacrificio" que significan el trabajo y el compromiso militante, el exiliado explica su rechazo por jugar el juego meritocrático de los premios y los beneficios de la sociedad en la que vive. En la sociedad de la abundancia, él elige una vida franciscana, de despojo. La opción es clara: "por los compañeros" (que siguen presos, en una primera etapa, pero que honrarán la opción de proletarización como lo hicieron los dirigentes tupamaros después de 1985), "por el pueblo uruguayo, que queda bajo las garras del régimen y que no tuvo la suerte de salir". La opción es clara también contra el aburguesamiento, y este punto se revelará particularmente importante: en tanto sociedad de la abundancia, todo el estilo de vida francés es implícitamente catalogado de burgués. Hasta tal punto de que un adjetivo suplanta el primero: ;ya te estás afrancesando!, se verá tal vez acusado quién aparezca con auto nuevo. La postura implica entonces una estrategia de exiliado que se basa en la distancia entre prescripciones y etiquetamientos sociales que al atravesar el Atlántico cambiaron de sentido porque se aplican ahora a una sociedad en la que no fueron concebidos. Adoptar el estilo de vida de una sociedad de consumo es como pecar de traición, como pasarse al bando del enemigo.

El problema se convertirá en una de las fuentes de conflicto más importantes entre los militantes exiliados. En un primer momento, cuando el exilio es visto por la mayoría sólo como una etapa (y no como una emigración definitiva), el mantenimiento de la distancia con la sociedad francesa presenta problemas menores. “¿Hasta qué punto vale la pena apren- 
der el idioma?", es una pregunta que tiene un tipo de respuesta si me pienso como uruguayo y si supongo que volveré. Pero cuando los meses de dictadura comienzan a ser largos en Montevideo y los inviernos parisinos insisten con la grisaille, la necesidad de integrarse se acentúa. La búsqueda de un trabajo se impone, los hijos aparecen, crecen y deben ir a la escuela. "Muchos empezaron a plantear la necesidad y el deseo de vivir como una persona normal". Es en ese cruce de corrimientos redoblados en el que reside la subjetividad del exiliado, esa figura particular del extranjero que está condenado a ser donde no está (¡qué suerte del español que conserva la distinción de esos dos verbos fundamentales y nos ahorra tanta explicación: ¿cómo será un exiliado francés?, pues il est la où il n'est pas. ¿Y la de un exiliado inglés?, pues he is where he isn't).

Volvamos ahora sobre la significativa historia de vida de Pedro, el "Francés", que él nos contó ya en ese asado y que hemos podido reconstruir más tarde en detalle a través de entrevistas. No tanto porque su biografía constituya un ejemplo típico, que no lo es, sino más bien porque la singularidad de su relato reúne, hipostasiado, el fenómeno del corrimiento característico de la subjetividad del exiliado. Soldado republicano, el padre de Pedro se refugió en Francia en 1939, donde pasó una buena parte de su exilio tras la guerra civil. Se instaló en las cercanías de Limoges donde tuvo dos hijos con su esposa, también española. "Primero los metieron en un campo de concentración, como a muchos de los españoles en esa época. Pero después él participó en la Resistencia, así que después de la guerra el PC francés lo ubicó en un pueblito donde le dieron casa porque la municipalidad era comunista. Le dieron una medalla de honor, nos cuenta el 'Francés'.' En 1952 la madre de Pedro muere en el parto junto con su tercer hijo. Solo, con dos niños, el padre decide partir hacia América ("Mi viejo no bancaba a los franceses. Nunca los bancó"). Primero intenta México, destino para el que no consigue visa, y finalmente parte rumbo al Uruguay en un barco que zarpa de Marsella. En Montevideo, el exiliado republicano se hizo carpintero en el barrio de Colón. Y habiendo nacido en Limoges, Pedro se convirtió naturalmente en el "Francés", mote que lo acompañará toda su vida. Tanto más desde que su padre — que "no bancaba a los franceses"- eligió el liceo de la elite intelectual montevideana para que él siguiera sus estudios: el Liceo Francés.

Como muchos de los otros exiliados españoles, el viejo republicano gozaba de una intachable reputación de combatiente. Oriunda también del barrio de Colón, Isabel, la mujer del Viejo Díaz lo recuerda así: "Era un vie- 
jo impresionante. ¡Laburaba!... Todos lo queríamos mucho en Colón. Era muy respetado." Así, tal vez impulsado un poco por el prestigio heroico del padre, otro poco por los aires del tiempo, y seguramente bastante por un convencimiento interior, que él identificaría con el "compromiso con la historia y con la suerte del pueblo", Pedro ingresa en el MLN-T a los veinte años. Se hace militante con una doble herencia paterna: sus ideas de combatiente (a través de las cuales, valga recordarlo, los viejos republicanos influenciaron en gran medida la formación de la guerrilla uruguaya ${ }^{14}$ y el oficio de carpintero. Pedro se integró en una columna ocupándose de la infraestructura: era el encargado de construir "berretines", pequeños escondrijos basándose en la simulación de dobles fondos de muebles, roperos, mesas, etc. Entre los tupamaros, el "Francés" adopta un nuevo nombre para la clandestinidad: se llama el "Gallego", inscribiéndose así más en la identidad de su padre que en su propia historia.

En 1972 Pedro emprende un viaje de regreso a su país natal, veinte años después de su partida: se exilia en Francia. ¿Puede alguien exiliarse en su país natal? Sí, él no puede vivir ese viaje más que como un destierro suplementario. Se siente perfectamente uruguayo, ese pequeño país en el que ha caído en prisión y que ahora lo expulsa en un avión. Corrimiento tras corrimiento, su identidad parece no terminar nunca de desplazarse. Pese a trabajar normalmente Pedro no vivirá nunca entre franceses durante los quince años de exilio en Francia, su país de origen. Su vida de destierro será entre los exiliados uruguayos, principalmente, más algún que otro chileno de esos que han llegado por miles tras la caída de la Unión Popular y entre los cuales se encuentra su futura mujer. Y los uruguayos, sarcasmo criollo mediante, señalarán el décalage permanente de Pedro, el "Gallego", nombrándolo con agua de otra pila bautismal: es en París que a Pedro comienzan nuevamente a llamarlo el "Francés". En Francia él parece una bola flotante entre dos campos que lo repelen: los franceses no pueden dejar de ver en él un extranjero, sus compañeros exiliados se distinguen de él recordándole por el epíteto burlón que él no es un auténtico oriental. Y así continuará Pedro desplazándose, estando allí donde no es. Construyendo el tiempo y el lugar a través de la proyección de otras coordenadas. En 1987 el "Francés" regresa a "su" país. Se vuelve a Montevideo con la familia que ha construido en el exilio. Su mujer chilena y sus hijos

14 Fernández Huidobro, Eleuterio: Historia de los Tupamaros, 3 vol., TAE, Montevideo, 19861987, volumen I, Los Orígenes. 
nacidos en París lo acompañan. Pero la cosa no funciona. Divorcio mediante, su mujer y sus hijos regresan poco después a Francia. Nadie logra integrarse ni enraizarse en ese país extranjero que es para ellos el Uruguay de finales de los años ochenta.

En Francia, el "Francés" había abandonado las filas tupamaras y cambiado así de grupo de referencia: pasó de los tupas a los bolches. Como todas las que toma, esa decisión tiene sentido en el corrimiento identitario que opera. Lo desplaza de su sociabilidad inmediata, pero lo acerca a un elemento de su historia (después de todo, su padre peleó con los comunistas franceses en la resistencia, y junto a ellos lo hizo en la República española). Pero cuando llega al Uruguay sólo le queda la casa paterna, aquella que construyeron juntos, donde él probablemente intente recomponer con retazos algún sentido de patria. Su familia lo deja, su padre murió en París y sus compañeros ya no son tales: él dejó a los tupamaros y los camaradas comunistas no lo reciben con los brazos abiertos. Pedro compra un taxi y recorre las calles de Montevideo durante otros quince años, entre 1987 y 2002. Seguramente fuma y piensa mientras conduce a sus pasajeros de un destino al otro. Destino, ¡qué extraña palabra en la existencia de un exiliado que parece no tener ninguno! ¿Le preguntará a las calles de la ciudad por su padre? ¿Buscará las huellas inexistentes de sus recorridos clandestinos cuando se jugaba la vida atravesando la ciudad en secreto? ¿Querrá saber qué pensaría su madre de esta ciudad en la que ella no lo puso en el mundo? ¿Cómo se sentirá cuando deja un pasajero en el shopping de Punta Carretas? ${ }^{15}$ ¿Intentará situar su celda entre las marquesinas? ¿Qué será de sus compañeros de París que hace tanto no ve? ¿Qué será de sus compañeros de Uruguay, unos que ya no lo son porque dejaron la militancia o porque ya no lo reconocen, otros porque tomaron otras opciones políticas que él mismo no admite?

Encontré a Pedro en 2003 de regreso en París. Media vuelta y vuelta entera como en la zamba... Buscaba una jubilación que le permitiera sobrevivir, aunque sabe que los años que trabajó en Francia no alcanzan para casi nada. Pero el "Francés" no busca instalarse en Francia. Quisiera irse a Barcelona. "Nunca banqué a los franceses", nos dice el francés, como repitiendo para sí la sentencia que atribuyó a su padre.

15 En la cárcel de Punta Carretas fueron encerrados los prisioneros políticos entre finales de los años sesenta y principios de los setenta. En los años noventa, en el edificio de la vieja cárcel, parcialmente demolido y renovado, se instaló uno de los principales centros comerciales de Montevideo. 


\section{Algunas observaciones extranjeras}

La historia del Francés representa un caso extremo y a la vez una especie de tipo ideal de ruptura social. No se encuentra inscrito en ningún colectivo, no participa en ningún sistema de intercambios sociales y así paga las consecuencias. Paradigma de la desafiliación es su condición errátil, impuesta por un mundo en el que no puede afincarse. Su caso no representa al conjunto de los exiliados uruguayos que en su mayoría lograron insertarse en la sociedad francesa o volvieron al Uruguay. Pero su caso permite ver con claridad algunos de los trazos principales de la experiencia social del exilio.

Mirando su propia condición de exiliado a través del prisma sociológico, Alfred Schütz escribió dos ensayos en los que intentó atrapar en la figura del extranjero algunas de las características generales de la relación del individuo con la sociedad. ${ }^{16}$ El tema de Schütz es la distancia en la que se encuentra el extranjero con respecto a la sociedad en la que se instala. Esa relación social está marcada por el desfase entre los modelos de acción que el recién llegado aprendió en su país de origen y aquellos que son propios a la sociedad que lo recibe. Según Schütz, el exiliado experimenta un choque provocado por la artificialidad que éste percibe en las normas de comportamiento del nuevo grupo. Lo que para los nacionales constituye el marco de referencia naturalmente "pertinente" para pensar y afrontar todo tipo de problemas, para el extranjero no son más que soluciones artificiales puesto que necesariamente difieren de aquellas otras adquiridas "naturalmente" en el país de origen. El extranjero debe comprender prácticamente todo lo que parece evidente a los miembros de la sociedad que lo recibe. Schütz dice que a los ojos del extranjero, "el modelo cultural del nuevo grupo no posee la autoridad de un sistema de recetas probadas precisamente porque éste no comparte ese modelo que ha sido formado en el interior de una tradición histórica vivaz", que no es la suya. El problema es irresoluble, pues esa "tradición histórica" no llega nunca a formar parte de la biografía del extranjero: "Tumbas y recuerdos son cosas que no se pueden transferir ni adquirir”. Schütz coloca así al extranjero en una posición

16 Alfred Schütz (Viena, 1899) muere en Estados Unidos en 1959, donde se había exiliado en julio de 1939. Los dos ensayos se encuentran reunidos en Schütz, Alfred: L'étranger, Allia, Paris, 2003 (1944 y 1945). 
fatal, pues si éste puede llegar a compartir presente y futuro de la nueva sociedad, "desde el punto de vista del nuevo grupo (la sociedad francesa, en nuestro caso), el extranjero es siempre un hombre sin historia". ${ }^{17}$

En una clave similar a la de Schütz, el alemán Georg Simmel también dio cuenta de la figura del extranjero. ${ }^{18}$ En él coincide con el enfoque del austriaco, según el cual la sociabilidad del extranjero está marcada por la distancia que separa su experiencia social de la de los miembros de la sociedad en la que vive. Sin embargo, para Simmel esta distancia define el lugar que el extranjero efectivamente ocupa en la sociedad. El extranjero no es quien permanece ineluctablemente separado, al margen de la sociedad. Extranjero es quien vive en un lugar sin haber formado parte del grupo desde el origen pero ocupa allí una posición definida: se encuentra integrado en la sociedad en tanto que extranjero. Hasta tal punto que le son reservadas ciertas actividades y hasta profesiones, como el comercio. El extranjero no es entonces errante, representa más bien una figura social que reúne en sí misma las dimensiones contrarias de la ruptura y la pertenencia. Puede quedarse e integrarse, pero siempre pesará sobre él la sospecha de querer partir en cualquier momento, de abandonar el barco frente a la primera dificultad. Como nuestros uruguayos, siempre habla de "volver".

¿En qué medida estas dos visiones corresponden con la evolución de la situación de exilio? Ambos autores permiten comprender un aspecto esencial de la relación de los exiliados con la sociedad. Puede pensarse que la visión de Schütz describe bien la situación de los exiliados al principio, mientras que la integración en la sociedad francesa no aparece como una opción. El análisis de Simmel, en cambio, parece corresponder a la situación de aquellos que deciden quedarse en Francia y de hecho dejan el exilio para convertirse en simples inmigrantes una vez terminada la dictadura en Uruguay y abiertas las posibilidades de retorno.

¿Qué ocurre si examinamos estas observaciones sobre la figura del extranjero desde el punto de vista de un exiliado político que ha vivido en un segmento relativamente corto de su existencia una historia tan fuerte como la de un militante clandestino: combate y muerte, traición y fidelidad, solidaridad, cárcel y destierro? Se observa que el militante de izquierda vivió ya un primer "exilio" al abrazar un proyecto revolucionario, mucho antes de exiliarse. La incorporación a un partido de izquierda radical pone

17 Ibídem, págs. 19-20.

18 Simmel, Georg: "Digressions sur l'étranger", en Grafmeyer, Y., et Joseph, I.: L'école de Chicago. Naissance de l'écologie urbaine, Paris, Aubier, 1984, págs. 53-59 (1904). 
a los militantes en situación de extranjería con respecto a la sociedad. El revolucionario rechaza las normas y el orden de la sociedad en la que vive, se distancia de ella y se integra en un nuevo grupo con el que comparte otros valores. La distancia crítica que construye en relación al orden social que quiere transformar desplaza al individuo hacia una nueva patria formada por su ideal, sus compañeros y camaradas. Los militantes de los años sesenta y setenta que entrevistamos en París dejaron círculos familiares, abandonaron carreras estudiantiles y profesionales o pusieron en juego sus puestos de trabajo mucho antes de caer en prisión o ser empujados al destierro. Esta posición se acentúa particularmente en el caso de quienes eligen el camino de la ilegalidad, y ella se redobla dramáticamente en momentos de proscripción, de represión, de persecución. Allí se vive una auténtica situación de exilio interno pues ya no es sólo el militante quien busca el distanciamiento, sino que éste es reforzado por el hecho de que el individuo es proscrito por la autoridad o por el poder.

Hemos mostrado ya en otro lugar cómo este fenómeno de la toma de distancia del militante con el orden social se redobla en el exilio, y hemos mostrado cómo se expresa ese fenómeno en la música popular. ${ }^{19}$ Las canciones de Daniel Viglietti, músico uruguayo exiliado en París expresan con claridad una parte importante del sentimiento colectivo del exiliado y probablemente ello sea una de las causas de su gran popularidad. Puede imaginarse el gran impacto emotivo de su Milonga de andar lejos cuando se la escucha fuera del país. El poema contiene toda la fuerza dramática que atraviesa la experiencia del exiliado, desgarrado entre dos mundos, lejos y sin embargo qué cerca. Al principio la milonga resuena lenta, con notas, gotas, que mojan el alma del uruguayo, y se acelera luego, violenta la voz de Viglietti, para romper el mapa y llamar urgente a la solidaridad: Ayúdeme, compañero, el dolor es mucho, Ayúdeme, no demore, que se nos viene el aguacero. Pero hay un hecho particularmente destacable: la canción no habla del exilio, fue compuesta antes y grabada en 1967. ¿Por qué una milonga de andar lejos? ¿Lejos de qué cuando se vive en el país y no se piensa dejarlo, se canta y se escribe para él? Lejos y sin embargo qué cerca: la imagen cartográfica no es en su origen más que la metáfora de la que se vale el poeta para cantar la distancia crítica a la realidad. No la del intelectual, sino la distancia en la que se funda un proyecto colectivo de

19 Allier, E., y Merklen, D.: "Milonga...", principalmente el apartado "Final cantado", págs. 366 ss. 
cambio radical de la realidad: Yo quiero romper la vida, cómo cambiarla quisiera, para formar el mapa de todos, y trazarlo codo con codo. En este poema se observa una gran densidad sociológica dada por un simbolismo complejo. La experiencia de los militantes de izquierda en el exilio es aquella de un desgarro simbólico redoblado de un apartamiento geográfico y cultural. El exilio viene a multiplicar las dimensiones del distanciamiento simbólico que el militante había realizado al criticar la sociedad y apartarse de ella para construir un proyecto de cambio: No somos los extrajneros, los extranjeros son otros. En otra canción grabada en 1968, siempre antes de exilio, Viglietti musicaliza un poema de Washington Benavides para cantarnos por qué él no es de por aquí. ${ }^{20}$ Una vez más, la canción pareciera anticipar la experiencia del exilio. El corazón del poeta está desvelado porque no es este pago mi pago/ que es otro que ya no sél si lo hayo. Para no quedar empantanado en la tragedia de ese lugar inexistente, que evidentemente no se encuentra ni en Uruguay ni en Francia, ese paraje que no hallo, el poema no puede sino deslizarse hacia la utopía de un lugar por construir, meter el hombro y alzarlo, en un proyecto de comunión.

\section{Milonga de andar lejos}

$\begin{array}{ll}\begin{array}{l}\text { Qué lejos está mi tierra } \\ \text { y sin embargo qué cerca, } \\ \text { o es que existe un territorio } \\ \text { donde las sangres se mezclan. }\end{array} & \begin{array}{l}\text { Los ríos son como venas } \\ \text { de un cuerpo entero extendido }\end{array} \\ \text { Tanta distancia y camino, } & \text { y es el color de la tierra } \\ \text { tan diferentes banderas, } & \text { la sangre de los caídos. } \\ \text { y la pobreza es la misma, } & \text { No somos los extranjeros, } \\ \text { los mismos hombres esperan. } & \text { los extranjeros son otros; } \\ \text { Yo quiero romper mi mapa, } & \text { son ellos los mercaderes } \\ \text { formar el mapa de todos, } & \text { y los esclavos nosotros. } \\ \text { mestizos, negros y blancos, } & \text { Yo quiero romper la vida, } \\ \text { trazarlo codo con codo. } & \text { como cambiarla quisiera. } \\ & \text { Ayúdeme, compañero; } \\ & \text { ayúdeme, no demore, } \\ & \text { que una gota con ser poco } \\ & \text { con otra se hace aguacero. }\end{array}$

Letra y música de Daniel Viglietti, in Canciones Para Mi América; disco grabado en La Habana, Montevideo y París, entre 1967 y 1968.

20 Viglietti, Daniel: Canto Libre, Sondor, Montevideo, 1969. 


\section{La eterna evocación}

Esto que les voy a contar me ocurrió como si fuese la segunda vez que lo vivía

Alfredo Zitarrosa ${ }^{21}$

El artículo que presentamos aquí se basa en una prolongada observación participante en el seno de la colonia de los uruguayos en París que se extendió entre 1996 y 2006. Lo esencial de esas observaciones fue realizado en La Parrilla, una de las estructuras asociativas creadas por los tupamaros. También fue realizada una serie de entrevistas (algunas en colaboración con Eugenia Allier) entre Montevideo y París, sin olvidar el análisis documental y bibliográfico.

Somos conscientes de que la actividad de la Parrilla no representa la totalidad del exilio uruguayo en París. Ha constituido sí uno de sus centros principales. Entre otras cosas su presencia condensa un fuerte valor histórico pues es la única institución de la época del exilio que aún pervive. No es casual que Tabaré Vázquez haya elegido ese lugar de encuentro para rendir homenaje a todos quienes fueron expulsados del país más de treinta años antes del triunfo electoral de la izquierda en Uruguay. Todos los viernes el asado, la música — presente a través de "cantores populares" residentes en París o de paso por la capital francesa- y el encuentro entre amigos y compatriotas anima la actividad. Con casi veinticinco años de actividad, la Parrilla llegó a convertirse en uno de los principales espacios de sociabilidad no solamente para uruguayos sino para latinoamericanos en general, principalmente argentinos.

Es tarde en la noche, tal vez sean las dos de la madrugada y la actividad de la Parrilla se termina siempre, como cada viernes. Después de que los últimos parroquianos deciden irse comienza el último tramo del trabajo de los militantes que animan el lugar. Limpiar todo, despejar el lugar y ordenar la totalidad de la vajilla y de los utensilios necesarios con los que tal vez una centena de visitantes venga a servirse el próximo viernes. Así llega un momento privilegiado para los militantes. Las puertas se cierran y una segunda cena es preparada para quienes trabajaron duro toda la noche. Un auténtico recitado de asado y vino comienza, y con él las historias que se rememoran. Increíbles sucesos que evocan encuentros y desencuentros vividos durante el exilio. A las preguntas reiteradas sobre aquellos de quienes no se tiene noticia se agrega un anecdotario que también se repite sin

21 Del cuento "La segunda vez", en Zitarrosa, Alfredo: Por si el recuerdo, Trilce, Montevideo, 1989, pág. 39. 
cesar. Pero hay un tercer tema de conversación mucho menos frecuentado, que no es en absoluto objeto de las conversaciones repetidas, pero que no por ello es menos central. Éste se relaciona más directamente con el pasado de las luchas clandestinas y con la represión. La presencia de ese pasado se encuentra frecuentemente en la base de la formación de la autoridad que organiza moralmente a la colonia de exiliados. Haber "pasado por la cana" (estar preso), "bancado la biava" (soportar la tortura), "estar en la pesada" (haber participado en hechos de armas), a veces haber perdido un ser querido en manos de la represión, son experiencias que fijan criterios de apreciación de unos sobre otros, pero que soportan el enorme peso de no poder ser dichos en público. No es posible instituir que la palabra de fulano no cuenta tanto como la de mengano que "este sí que la sufrió". Estas vivencias ligadas al sufrimiento y a una conducta individual respecto al grupo (no denunciar a sus compañeros bajo la tortura, es el ejemplo primordial, pero ser calificado de incondicionalmente "solidario" es otro que reviste no menos valor) son conocidas por todos pero evocadas únicamente en situación de confidencia y, salvo raras excepciones, jamás en público.

Sin duda los mecanismos de selección de lo que se dice y de lo que no, de lo que permanece en silencio y de lo que es evocado como una rememoración repetitiva, pueden ser descifrados a partir de una conceptualización freudiana del "síntoma", sobre todo si pensamos en situaciones tan traumáticas como las que atraviesan las vidas de los exiliados. Podemos también poner el acento en el modo en que estas conversaciones ayudan a estructurar a la vez la sociabilidad y la experiencia que los exiliados tienen de su situación presente y de su pasado. Por quién se pregunta y quién no es evocado, el rol que se asigna a cada miembro del grupo en el anecdotario, las chanzas y las bromas reiteradas sobre fulano o mengano contribuyen al mantenimiento de un lazo simbólico que une a los exiliados entre sí. La conversación, con su forma repetitiva, prolonga la reunión hasta la madrugada, impide la partida, contribuye a permanecer juntos, a atenuar el sufrimiento provocado por la distancia y a evitar un aislamiento que puede acarrear consecuencias dramáticas. Pero ese "permanecer juntos" no se hace sin violencia simbólica, y esa violencia los exiliados la llevan hasta la expulsión de los compatriotas que no se adaptan a las normas del grupo. Pero esta forma del destierro en el destierro nunca es sancionada por una sentencia explícita. Se realiza por un simple paso a silencio de personas que desaparecen de la comunidad y de sus repetitivas evocaciones.

Recibido el 10 de enero de 2007

Aceptado el 15 de marzo de 2007 